\title{
Exploring links between genotypes, phenotypes, and clinical predictors of response to early intensive behavioral intervention in autism spectrum disorder
}

\author{
Valsamma Eapen ${ }^{1,2}{ }^{*}$, Rudi Črnčec ${ }^{2}$ and Amelia Walter ${ }^{1,2}$ \\ ${ }^{1}$ Academic Unit of Child Psychiatry South West Sydney, South Western Sydney Local Health District, Liverpool, NSW, Australia \\ ${ }^{2}$ School of Psychiatry, University of New South Wales, Sydney, NSW, Australia
}

\section{Edited by:}

Andrew Whitehouse, Telethon Institute for Child Health Research, Australia; University of Western Australia, Australia

\section{Reviewed by:}

Elisa L. Hill-Yardin, The University of Melbourne, Australia

Naomi E. Bishop, La Trobe University, Australia

${ }^{*}$ Correspondence:

Valsamma Eapen, Academic Unit of Child Psychiatry South West Sydney, ICAMHS, Mental Health Centre L1, Locked Bag 7103, Liverpool BC, NSW 1871, Australia

e-mail:v.eapen@unsw.edu.au
Autism spectrum disorder (ASD) is amongst the most familial of psychiatric disorders. Twin and family studies have demonstrated a monozygotic concordance rate of 70-90\%, dizygotic concordance of around $10 \%$, and more than a 20 -fold increase in risk for first-degree relatives. Despite major advances in the genetics of autism, the relationship between different aspects of the behavioral and cognitive phenotype and their underlying genetic liability is still unclear. This is complicated by the heterogeneity of autism, which exists at both genetic and phenotypic levels. Given this heterogeneity, one method to find homogeneous entities and link these with specific genotypes would be to pursue endophenotypes. Evidence from neuroimaging, eye tracking, and electrophysiology studies supports the hypothesis that, building on genetic vulnerability, ASD emerges from a developmental cascade in which a deficit in attention to social stimuli leads to impaired interactions with primary caregivers. This results in abnormal development of the neurocircuitry responsible for social cognition, which in turn adversely affects later behavioral and functional domains dependent on these early processes, such as language development. Such a model begets a heterogeneous clinical phenotype, and is also supported by studies demonstrating better clinical outcomes with earlier treatment. Treatment response following intensive early behavioral intervention in ASD is also distinctly variable; however, relatively little is known about specific elements of the clinical phenotype that may predict response to current behavioral treatments. This paper overviews the literature regarding genotypes, phenotypes, and predictors of response to behavioral intervention in ASD and presents suggestions for future research to explore linkages between these that would enable better identification of, and increased treatment efficacy for, ASD.

Keywords: autism spectrum disorder, genotype, phenotype, early intervention, treatment response

\section{GENETIC BASIS OF AUTISM SPECTRUM DISORDER}

It has been suggested that autism spectrum disorder (ASD) is one of the most familial of psychiatric disorders, with a heritability of $80 \%$, a monozygotic concordance rate of $70-90 \%$, dizygotic concordance of around $10 \%$, and more than a 20 -fold increase in risk for first-degree relatives (Bailey et al., 1995; O’Roak, 2008). Although there have been some significant advances in the recent past (Wang et al., 2009; Pinto et al., 2010), the rate of progress in gene discovery has been modest (Abrahams and Geschwind, 2010). Also, genomic analyses indicate extreme genetic heterogeneity and so far, over 100 genes have been reported in ASD with a conservative estimate of between 380 and 820 loci implicated (Betancur, 2011; Clarke and Eapen, in press), and with considerable overlap with other disorders such as intellectual disability, epilepsy, schizophrenia, and attention deficit hyperactivity disorder (ADHD). These findings suggest that ASD is not a single-gene disorder with Mendelian inheritance but rather a complex disorder resulting from simultaneous genetic variations in multiple genes (Dawson et al., 2002; El-Fishawy, 2010) as well as complex interactions between genetic, epigenetic, and environmental factors (Eapen, 2011).

It has been reported that some of the associated sequence variations noted in ASD are common in the general population although it is unclear as to whether the ASD phenotype results from the involvement of single genes in combination with nongenetic factors, or multiple genes through locus heterogeneity (multiple rare variations in the same gene), or multiple genes through allelic heterogeneity (variations in multiple and different genes). Furthermore, it has been proposed that multiple genes in combination with non-genetic factors may be necessary to result in the ASD phenotype or that ASD may be a collection of rare disorders, that is, a shared phenotype resulting from several different genetic defects. Thus it would seem that there are at least three major pathogenetic processes (Eapen, 2011) resulting in three different subgroups: (1) ASD-Plus group or Syndromic ASD resulting from rare single-gene disorders where ASD is a behavioral phenotype of the associated disorder; (2) Broad ASD group resulting from common variants distributed continually in 


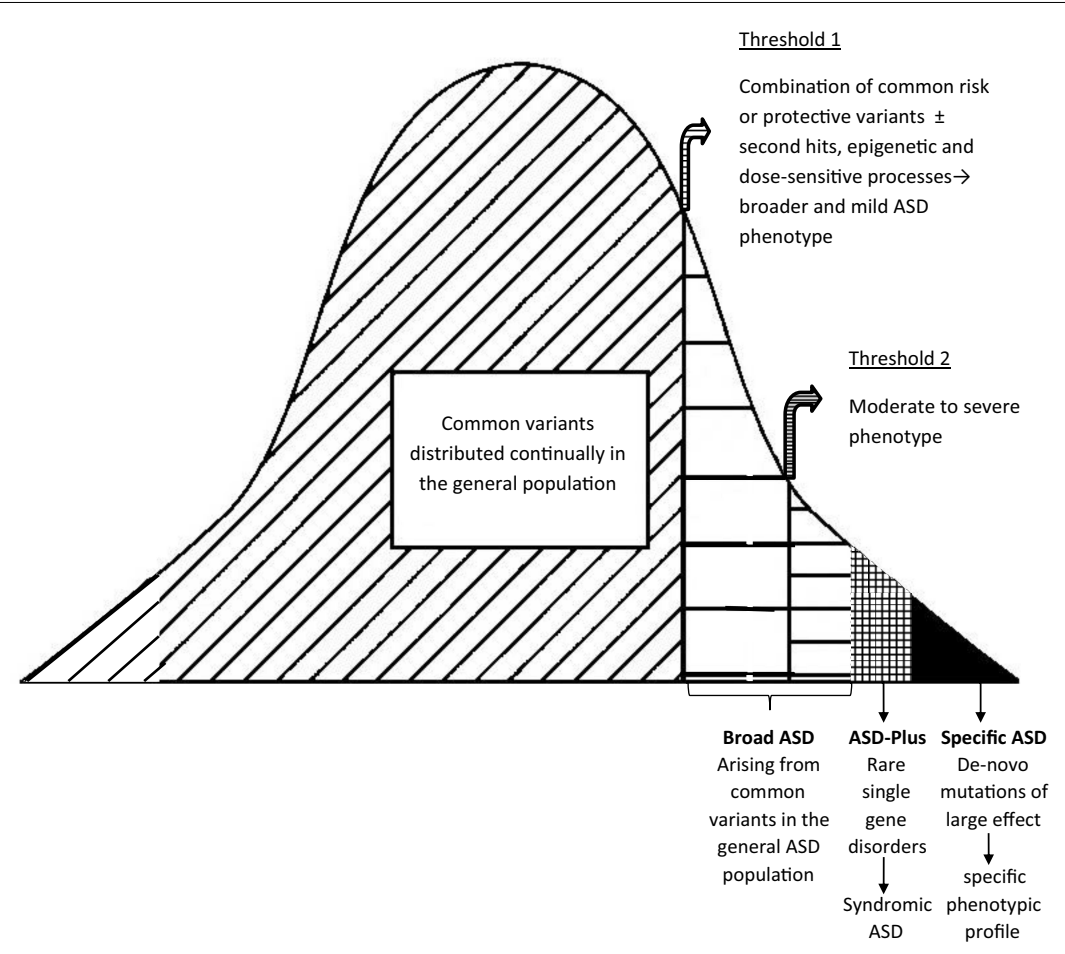

FIGURE 1 | Genetic and phenotypic heterogeneity in ASD. Adapted from Eapen (2011).

the general population but following a gene-environment diathesis model, when it passes the first threshold (threshold 1) due to other gene or environmental additive effects or "second hits" including epigenetic and dose-sensitive processes, it results in the broader and mild ASD phenotype which may be observed in other family members of affected individuals and when it passes a second threshold (threshold 2) it results in a moderate to severe ASD phenotype that is clinically significant; and (3) specific ASD group due to "de novo mutations" of large effect resulting in ASD presentations but carrying unique phenotypic profiles based on the specific site and nature of the de novo mutation (see Figure 1).

\section{BROAD AUTISM PHENOTYPE}

The term "broad autism phenotype" (BAP) refers to the presence of subclinical levels of ASD symptoms among individuals who do not meet criteria for a diagnosis of ASD (Bolton et al., 1994; Piven and Palmer, 1999). BAP characteristics correspond to the primary features of ASD, including traits that are social, such as socially reticent or inappropriate behavior, or non-social, such as rigidity and ritualistic or repetitive behaviors (Losh et al., 2009). Twin and family studies have shown that genetic liability to autism is expressed in unaffected relatives of people with ASD through features that are milder but qualitatively similar to the defining characteristics of ASD, including social abnormalities, communication impairments, and repetitive behaviors (Bailey et al., 1998; Goussé et al., 2002; Losh et al., 2009). Previous studies suggest that around 25\% of first-degree relatives of children with ASD show impairment in one of the three diagnostic domains for ASD: sociability, communication, and cognitive or behavioral flexibility (for a review, see
Goussé et al., 2002). Bailey et al. (1998) conclude that the BAP features observed in relatives of individuals with ASD appear to have a genetic rather than environmental basis.

While early work on the BAP focused on examining ASDrelated traits in first and second degree relatives of individuals with ASD (for a review, see Bailey et al., 1998), subsequent studies have demonstrated that the characteristics comprising the BAP exist within the general population as well (Baron-Cohen et al., 2001; Constantino and Todd, 2003, 2005). Features of ASD that have been found to be continuously distributed within the general population include restricted interests (Baron-Cohen et al., 2001), atypical visuospatial and cognitive performance (Grinter et al., 2009; Stewart et al., 2009; Richmond et al., 2013), abnormal speech perception (Stewart and Ota, 2008), reduced gaze reciprocity (Chen and Yoon, 2011), an impaired ability to recognize affect from facial expressions and body language (Ingersoll, 2010b), and reductions in social skill and social-cognitive ability (Sasson et al., 2012). These findings may be consistent with the suggestion that some of the genetic sequence variations found in ASD are common in the general population.

\section{HETEROGENEITY OF AUTISM}

Despite major advances in the genetics of ASD, the relationship between different aspects of the behavioral and cognitive phenotype of ASD and their underlying genetic liability is still unclear (Bailey et al., 1998; Klin et al., 2002). This is complicated by the heterogeneity of ASD, which exists at both genetic and phenotypic levels (Charman et al., 2011). Further, it has been suggested that there may be gender dependent differences in the ASD phenotype 
(Eapen, 2011). For example, Lai et al. (2012) observed that while performance in the social-cognitive domain was equally impaired in male and female adults with ASD, in the specific non-socialcognitive domains of attention to detail and dexterity involving executive function, there were differences based on gender. Losh et al. (2009) argue that the BAP may provide an important complementary approach for detecting the genes involved in ASD by narrowing the highly heterogeneous phenotype of an ASD diagnosis to particular features that are likely to be more conducive to genetic investigation (Wheelwright et al., 2010; Spencer et al., 2011, 2012a,b; Sucksmith et al., 2012).

Due to its heterogeneity, ASD is no longer viewed as a narrowly defined, categorical disorder, but instead as a spectrum of conditions that affect individuals differently (Wing, 1996). Some researchers have suggested that there are probably many "autisms" with different underlying biological processes and developmental pathways (Elsabbagh, 2012). The term ASD is now commonly used to describe a range of neurodevelopmental conditions that show considerable phenotypic heterogeneity at any one age and across development, and that are likely to differ in underlying etiology (Geschwind and Levitt, 2007). However, they all generally share a primary impairment in social relatedness and reciprocity, an "insistence on sameness," and impairments in the use of language for communication, which is in keeping with Kanner's (1943) description of classically "autistic" children.

It is noteworthy that genetic heterogeneity leads to clinical heterogeneity. For example, similar or identical mutations can result in very broad phenotypic variations as is evident from studies investigating endophenotypes exhibited by patients expressing mutations in the CNTNAP2 gene (Eapen, 2011). Such studies demonstrate a role for CNTNAP2 in schizophrenia, epilepsy, Tourette's syndrome, and obsessive compulsive disorder (Verkerk et al., 2003; Friedman et al., 2008). Alternatively, ASD cases resulting from different genetic lesions can have clinically distinct presentations (Bruining et al., 2010). However, such distinct phenotypic presentations are masked by the limitations of diagnostic categories. Therefore, future studies exploring risk alleles should examine homogenous and heritable endophenotypic traits rather than diagnostic groups. Thus, given the significant genotype to phenotype heterogeneity, one method to find homogeneous entities and link these with specific genotypes would be to pursue endophenotypes.

\section{ENDOPHENOTYPES IN ASD}

Neurocognitive profiles and neurophysiological changes observed using neuroimaging, eye tracking, and electrophysiological techniques are commonly reported in individuals with ASD. Studies of head circumference and imaging studies of brain morphometry have found evidence of increased brain growth beginning within the first year of life (Courchesne et al., 2005), while functional brain imaging in older children and adults has shown abnormal patterns of interactions between brain regions, possibly related to aberrant connections being laid down during earlier stages of development (Courchesne et al., 2011). One model relating these early abnormalities in brain development to the characteristic sociocommunicative impairments has hypothesized that early low-level deficits in recognition and orientation toward social stimuli lead to a lack of social engagement with primary caregivers during infancy, resulting in decreased exposure to the reciprocal social interactions critical for healthy development of brain circuits responsible for normal social behavior (Dawson, 2008).

Basic, low-level impairments of social attention and reciprocity are thought to relate to the socio-communicative impairments characteristic of ASD and are evident in children with ASD from as early as the first year of life. For example, home videos of 12month-olds later diagnosed with ASD demonstrate reduced visual attention to people and failure to respond to vocal approaches (Werner et al., 2000; Osterling et al., 2002; Werner and Dawson, 2005), while other studies have shown poor verbal imitation (Sallows and Graupner, 2005). Prospective studies of children at high risk of ASD show similar results (Nadig et al., 2007). Young children with ASD also show a lack of joint attention and failure to coordinate attention and share their experiences with caregivers (Charman, 2003). Researchers using preferential looking techniques have identified a reduction in autistic toddlers' preference for viewing biological motion (Klin et al., 2009) and hearing the human voice (e.g., Klin, 1991; Dawson et al., 1998, 2004).

Similarly, eye gaze abnormalities have been described as indicative of later development of ASD (Bedford et al., 2012; Elsabbagh et al., 2012). Using eye tracking technology, Jones et al. (2008) found that 2-year-olds with ASD lacked the normal bias to attend to the eyes when watching videos of people, replicating earlier studies with autistic adolescents (Klin et al., 2003; see also Norbury et al., 2009) and confirming clinical reports of reduced eye contact in ASD (Zwaigenbaum et al., 2005). Psychophysical evidence suggests that differences in spatial localization between individuals with ASD and controls begins at an early cortical stage of visual processing (Latham et al., 2013). Further evidence comes from electrophysiology. Pre-school and school-aged children with ASD produce atypical cortical event-related potentials (ERPs) in response to deviations in streams of speech stimuli, despite normal responses to deviants in streams of non-speech stimuli (Kuhl et al., 2005; Lepistö et al., 2005; Ceponiene et al., 2005; Whitehouse and Bishop, 2008). Kuhl et al. (2013) compared brain responses to word stimuli between typically developing children and children with ASD, categorized into two groups according to the severity of their social symptoms. They found that the brain activity of children with ASD with less severe social symptoms resembled that of the typically developing controls, while children with ASD with more severe social symptoms showed a clearly atypical brain response. Furthermore, the ERP response among children with ASD at time 1 (when they were 2 years old) was found to predict receptive language, cognitive ability, and adaptive behaviors at two follow-up time points, when the children were 4 and 6 years old (Kuhl et al., 2013). Similarly, school-aged children are reported to show abnormal brainstem evoked responses (ABR) to trains of speech stimuli but not click sounds (Russo et al., 2009), and these abnormalities are linked to clinical assessments of language abilities.

Recognition of facial emotions has also been found to be impaired in children and adults with ASD compared to controls (Sucksmith et al., 2012; Oerlemans et al., 2013). The reduced activation in brain regions associated with facial processing in people with ASD relative to control subjects has been shown to 
be correlated with the clinical severity of their impairment in reciprocal social interaction (Spencer et al., 2012b). Finally, studies using electromyography (EMG) to measure facial muscle activity have shown a reduction or delay in the normal tendency to (subconsciously) mimic emotional expressions when viewing pictures of faces (McIntosh et al., 2006; Oberman et al., 2009).

Further, it is widely argued that many of the symptoms of ASD are caused by aberrant neural connectivity (e.g., Brock et al., 2002; Geschwind and Levitt, 2007), including specific findings such as reduced functional connectivity within and between "social" resting state networks in ASD (von dem Hagen et al., 2013) as well as significantly increased gray matter volume in the anterior temporal and dorsolateral prefrontal regions and significant reductions in the occipital and medial parietal regions compared with controls (Ecker et al., 2012). These findings imply that a key component of behavioral intervention may be to compensate for such early deficits and that behavioral intervention should occur as early as possible to normalize the developmental trajectory and avoid downstream effects. Thus baseline performance on neurocognitive responses to socially relevant stimuli might predict the magnitude of clinical and cognitive improvement following behavioral intervention. Recent research suggests that early behavioral intervention may be associated with normalized brain activity in young children with ASD. Previous studies have demonstrated that children receiving the Early Start Denver Model (ESDM), a behavioral intervention for children with ASD, showed gains in IQ and adaptive behavior and decreases in ASD-specific symptoms after intervention (Dawson et al., 2010; Eapen et al., 2013; Vivanti et al., 2013). In a recent study, Dawson et al. (2012) found that typically developing children and children with ASD who had been treated with the ESDM showed more cortical activation and allotted greater attentional and cognitive resources to social stimuli than to non-social stimuli, while children with ASD who had received community-based behavioral intervention showed the reverse pattern.

\section{BEHAVIORAL AND COGNITIVE PHENOTYPES IN ASD}

There are increasing efforts to determine and refine subtypes within the ASD behavioral phenotype (e.g., Ingram et al., 2008; Munson et al., 2008a,b; Frazier et al., 2010), with contemporary studies using large samples and sophisticated statistical approaches such as taxometric and latent variable models. To date, however, few distinct behavioral subtypes have been identified, and none is yet well replicated - frustrating efforts to "carve nature at the joints." Ingram et al. (2008) provided the first taxometric analysis of ASD and sought to test putative ASD subgrouping paradigms based on seven phenotypes which vary within the ASD population: social interaction/communication, intelligence, adaptive functioning, insistence on sameness, repetitive sensory motor actions, language acquisition, and essential/complex physical phenotype. The "complex" physical phenotype was defined according to the presence of physical dysmorphology and/or microcephaly, indicating some abnormality of early morphogenesis, whereas the "essential" physical phenotype referred to the remainder of individuals with ASD without these features (Miles et al., 2005). The authors indicated that valid subgroups could be constructed using the social interaction/communication, intelligence, and essential/complex paradigms, whereas the other phenotypes were found to exhibit results consistent with a dimensional structure. Given intelligence is consistently described as one of the primary aspects of heterogeneity in ASD, Munson et al. (2008a) sought to explore whether there were distinct ASD subtypes based upon IQ. Four latent classes were ultimately identified that represented different levels of intellectual functioning as well as different patterns of relative verbal versus non-verbal abilities. Moreover, group membership was related to adaptive functioning and social impairment, above and beyond the direct relationship of verbal and non-verbal IQ (Munson et al., 2008a). In a different study, Munson et al. (2008b) reported that specific aspects of neurocognitive functioning appear to be important predictors of developmental variability during the pre-school years in children with ASD. In particular, learning of reward associations and imitation from memory and novelty preference were significantly related to Vineland socialization and communication growth rates above and beyond non-verbal problem solving ability. A review of factor analytic studies showed that, of the seven studies included, six found evidence for multiple factors underlying autistic features (Mandy and Skuse, 2008). The majority of studies reported at least one social-communication factor and all but one also reported at least one distinct non-social factor comprising repetitive interests, behaviors and activities, however, the total number of factors reported varied.

In a large scale study employing taxometric and latent variable models, Frazier et al. (2010) concluded that the available literature and study results implied a categorical model of ASD, with two to three subdimensions - social communication, repetitive/perseverative behavior, and possibly social motivation - best reflecting the structure of ASD symptoms. Related work by the same group yielded similar results and provided broad support for DSM5 ASD criteria (Frazier et al., 2012). This finding is somewhat at odds with the related body of literature that has concluded that ASDs represent the severe end of a quantitative trait or continuum of social behavior, and the differing conclusions may reflect differing theoretical and statistical approaches. It is of course also possible that both viewpoints are correct and that categorical and dimensional aspects of ASD symptoms should be considered in the conceptualization of ASD.

There is increasing momentum within the literature to conceive of the core ASD symptomatology as distinct, or "fractionable." That is, that while the core features may regularly co-occur, these features may have distinct causes at genetic, cognitive, and neural levels. In their seminal review paper, Happe et al. (2006) argue that "it is time to give up on the search for a monolithic cause or explanation for the three core aspects of autism" (p. 1219). This claim was based in part on Ronald and colleagues' work on a large UK general population twin sample which found that correlations between continuous measures of social, communication and repetitive behavior were lower than expected (Happe et al., 2006). Happe et al. describe several implications following from their thesis, including that at the behavioral level each aspect of the ASD behavioral triad needs to be assessed separately rather than using global rating scales. The authors also claim that "heterogeneity in ASD, on our account, is not simply due to noise or the complex unfolding of development, but is an unavoidable consequence of 
variation along at least three largely independent (although of course interacting) dimensions of impairment" (p. 1220).

A large number of studies have also explored the ASD cognitive phenotype and a number of cognitive models of ASD have been proposed over time. These include the theory of mind account (Baron-Cohen et al., 1985); the executive dysfunction account (Ozonoff et al., 1991); the weak central coherence account (Happe and Frith, 2006); the enhanced perceptual functioning account (Mottron et al., 2006); the theory of reduced generalization and enhanced discrimination ability (Plaisted, 2001); and the empathizing - systematizing theory (Baron-Cohen, 2010; Grove et al., 2013). Each of these cognitive characteristics has been successfully linked to specific aspects of the ASD behavioral phenotype (Taylor et al., 2012) although none would appear to provide a parsimonious account of features observed in ASD. Charman et al. (2011) provide an excellent review of studies in this area and also a compelling account of the potential benefits of articulating ASD cognitive phenotypes with respect to advancing both treatment and genetic research. Charman also highlights the challenges involved in conducting high quality research in this area from statistical and methodological perspectives.

\section{VARIABILITY IN AND PREDICTORS OF RESPONSE TO BEHAVIORAL TREATMENT IN ASD}

The heterogeneity of ASD may also underlie the variability in response to treatment that is observed among individuals with ASD. Meta-analyses conducted in recent years have tended to conclude that Early Intensive Behavioral Intervention (EIBI), incorporating the principles of applied behavior analysis (ABA), is the treatment of choice for young children with ASD (Vismara and Rogers, 2010; Reichow, 2012), and that superior outcomes are associated with entry into EIBI at the earliest possible age (Granpeesheh et al., 2009; Wallace and Rogers, 2010). Despite the efficacy of EIBI for some children, there is tremendous variation in treatment response in ASD, with other children who receive EIBI failing to have a dramatic response (Dawson et al., 2002). A systematic review of controlled studies of EIBI showed that, while EIBI resulted in improved outcomes for children with ASD compared to comparison groups at a group level, there was marked variability in outcome at an individual level (Howlin et al., 2009). This differential response to treatment is common across all of the evidence-based approaches for treatment of ASD, with up to $50 \%$ of children showing substantial positive gains, and the other $50 \%$ making variable progress, some with extremely limited skills development (Stahmer et al., 2011).

Therefore, research aimed at methods of individualizing treatment is important. Such research requires an understanding of the pre-treatment characteristics associated with differential response to treatment, including child and family variables, and how specific behavioral intervention techniques address each of these characteristics (Stahmer et al., 2011). The goal of this line of research is to allow treatments to be tailored to individual children and thereby increase the overall rate of positive outcomes for children with ASD (Stahmer et al., 2011). In a recent systematic review of EIBI for ASD, however, Warren et al. (2011) concluded that the ability to predict children's response to treatment and outcome was very limited and warranted further investigation. The genetic and phenotypic heterogeneity inherent in ASD may also imply that no single EIBI can be universally effective and that, in a sense, many nuanced treatment approaches may ultimately be required for the many autisms in existence.

Nonetheless, available evidence indicates that a number of pretreatment factors may be associated with response to treatment across various EIBI models. These include overall IQ (McEachin et al., 1993; Harris and Handleman, 2000; Eldevik et al., 2006; Magiati et al., 2007; Remington et al., 2007; Perry et al., 2011), language and communication abilities (Sallows and Graupner, 2005; Eldevik et al., 2006; Eikeseth et al., 2007; Magiati et al., 2007; Remington et al., 2007), adaptive skills (Remington et al., 2007; Makrygianni and Reed, 2010; Flanagan et al., 2012), imitation (Sallows and Graupner, 2005; Vivanti et al., 2013), play skills (Kasari et al., 2008, 2012; Ingersoll, 2010a), joint attention (Yoder and Stone, 2006; Kasari et al., 2008), interest in objects (Yoder and Stone, 2006; Schreibman et al., 2009; Carter et al., 2011), functional use of objects (Vivanti et al., 2013), symptom severity (Smith et al., 2000; Sallows and Graupner, 2005; Remington et al., 2007; Vivanti et al., 2013), and younger age (Harris and Handleman, 2000; Perry et al., 2011). Some studies, however, have failed to find relationships between these factors and treatment response. For example, Eldevik et al. (2006) found that age at intake was not a predictor of children's response to a low-intensity behavioral treatment, while Sallows and Graupner (2005) found that initial IQ did not predict children's response to an intensive behavioral intervention. Furthermore, the direction of relationships between these pre-treatment factors and intervention response is sometimes inconsistent. For example, Remington et al. (2007) found that higher ASD symptom scores at intake were associated with improved EIBI outcomes, while Smith et al. (2000) found that children with milder symptoms (i.e., a diagnosis of Pervasive Developmental Disorder-NOS) tended to have a better response to EIBI than children with more severe symptoms (i.e., a diagnosis of ASD).

\section{INCREASING TREATMENT EFFICACY FOR ASD BY IDENTIFYING INDIVIDUAL DIFFERENCES}

Given the heterogeneity of ASD, it is likely that a personalized medicine approach, considering individual differences in etiologic and phenotypic characteristics, would result in increased treatment efficacy (Perrin et al., 2012). Georgiades et al. (2013) suggest that, rather than conducting studies that compare individuals with a diagnosis of ASD with typically developing individuals, future research should focus on understanding the meaning of individual and subgroup differences within the autism spectrum on treatment outcomes. The identification of such differences, and an understanding of how these might impact on response to treatment, has implications for the ability to individually tailor treatment programs and thereby improve their effectiveness.

As an example, this type of approach has been found to be useful in explaining differences in presentation and treatment response in children with diagnoses of oppositional defiant disorder and conduct disorder. There is increasing support for the subtyping of childhood conduct problems based on whether children exhibit high versus low levels of callous-unemotional (CU) traits, such as a lack of guilt and empathy (Hawes et al., 2013). Research suggests 
that the conduct problems of children with high levels of CU traits are more severe and less responsive to established psychological interventions than those of children without CU traits (Hawes and Dadds, 2005; Waschbusch et al., 2007). This has allowed research into interventions that may contribute to reductions in the $\mathrm{CU}$ traits of young children (Hawes and Dadds, 2007; McDonald et al., 2011). Furthermore, articulating these phenotypic differences has contributed to a better understanding of the etiology of conduct disorder (e.g., Viding et al., 2007).

One method to potentially identify subgroups among children with ASD would be to investigate phenotypic characteristics that may predict response to treatment, which has important implications for guiding choice of treatment. Furthermore, using a longitudinal design, it would be beneficial to compare the developmental trajectory of young children with ASD receiving a standardized treatment with those in "waitlist" conditions as well as with healthy control groups. This would provide a significant contribution to the sparse body of knowledge about developmental changes in brain function during this period of development. Even more importantly, determining which characteristics correspond with observable changes in the treatment group would allow us to identify specific individual characteristics and relevant biomarkers sensitive to behavioral intervention, with implications for assessing response to intervention in clinical and research settings (see Figure 2). This would also reveal whether and which variations in the baseline measures of brain function predict response to treatment. Given the significant investment represented by EIBI programs, their overall utility could be greatly enhanced by determining whether there are measurable characteristics at baseline capable of predicting response. Finally, if such phenotypic

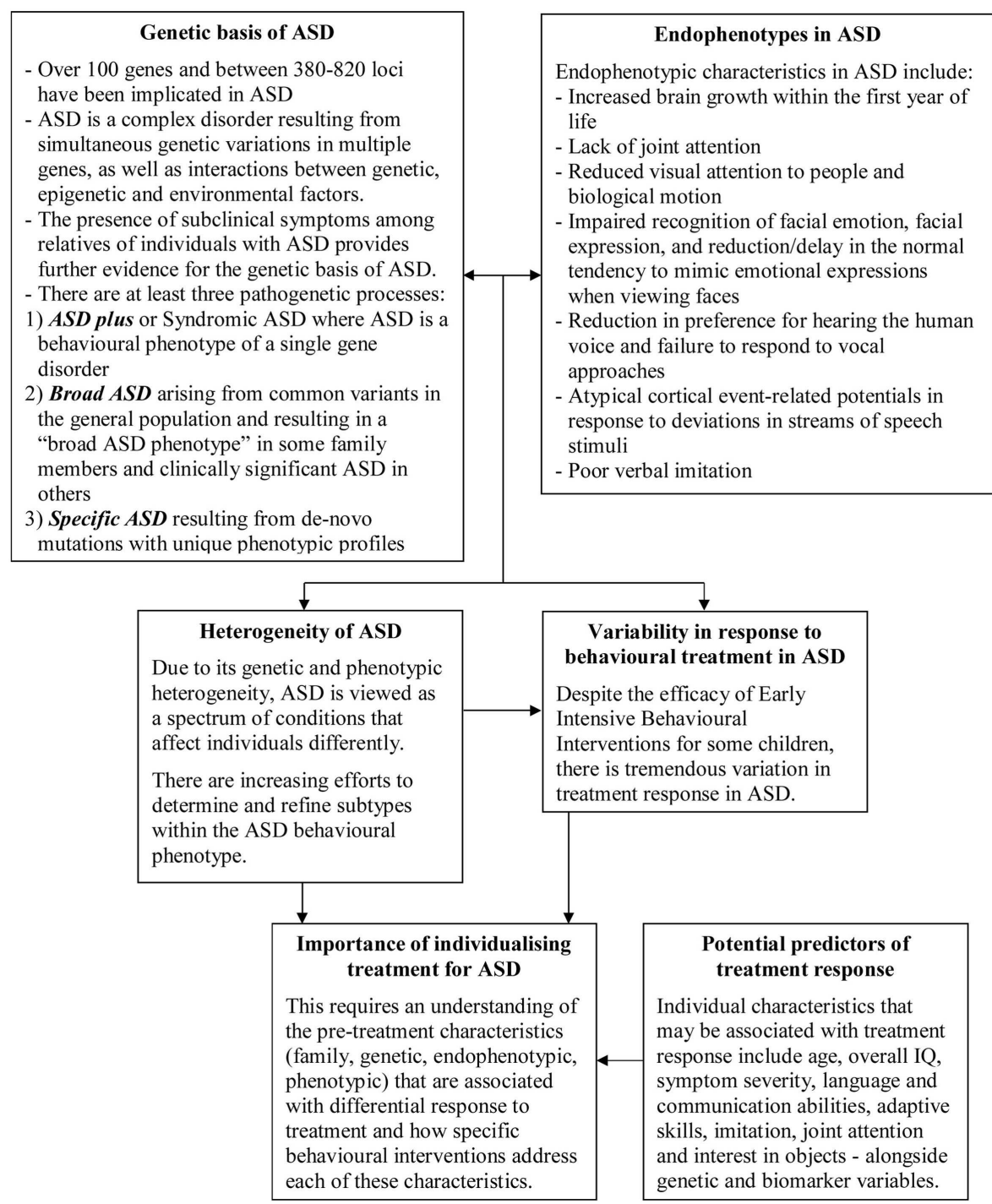

FIGURE 2 | Summary of key points and links between genotypes, endophenotypes, and clinical predictors of response to behavioral intervention in ASD. 
predictors were established, this could further our understanding of the genetic basis of ASD, by allowing future research to attempt to link these predictors to specific underlying genetic causes. The

\section{REFERENCES}

Abrahams, B. S., and Geschwind, D. H. (2010). Connecting genes to brain in the autism spectrum disorders. Arch. Neurol. 67, 395. doi:10.1001/ archneurol.2010.47

Bailey, A., Le Couteur, A., Gottesman, I., Bolton, P., Simonoff, E., Yuzda, E., et al. (1995). Autism as a strongly genetic disorder: evidence from a British twin study. Psychol. Med. 25, 63-77. doi:10.1017/ S0033291700028099

Bailey, A., Palferman, S., Heavey, L., and Le Couteur, A. (1998). Autism: the phenotype in relatives. J. Autism Dev. Disord. 28, 369-392. doi:10.1023/A: 1026048320785

Baron-Cohen, S. (2010). "Empathizing, systemizing and the extreme male brain theory of autism," in Progress in Brain Research: Sex Differences in the Human Brain, Their Underpinnings and Implications, ed. I. Savic (Cambridge: Academic Press), 167-176.

Baron-Cohen, S., Leslie, A. M., and Frith, U. (1985). Does the autistic child have a "theory of mind"? $\operatorname{Cog}$ nition 21, 37-46. doi:10.1016/00100277(85)90022-8

Baron-Cohen, S., Wheelwright, S., Skinner, R., Martin, J., and Clubley, E. (2001). The autism-spectrum quotient (AQ): evidence from Asperger syndrome/high-functioning autism, males and females, scientists and mathematicians. J. Autism Dev. Disord. 31, 5-17. doi:10.1023/A: 1005653411471

Bedford, R., Elsabbagh, M., Gliga, T., Pickles, A., Senju, A., Charman, T., et al. (2012). Precursors to social and communication difficulties in infants at-risk for autism: gaze following and attentional engagement. J. Autism Dev. Disord. 42, 2208-2218. doi:10.1007/s10803012-1450-y

Betancur, C. (2011). Etiological heterogeneity in autism spectrum disorders: more than 100 genetic and genomic disorders and still counting. Brain Res. 1380, 42-77. doi:10. 1016/j.brainres.2010.11.078

Bolton, P., MacDonald, H., Pickles, A., Rios, P., Goode, S., Crowson, M., et al. (1994). A case-control family history study of autism. J. Child Psychol. Psychiatry 35, 877-900. doi:10.1111/ j.1469-7610.1994.tb02300.x

Brock, J., Brown, C. C., Boucher, J., and Rippon, G. (2002). The temporal binding deficit hypothesis of autism.
Dev. Psychopathol. 14, 209-224. doi: 10.1017/S0954579402002018

Bruining, H., de Sonneville, L., Swaab, H., de Jonge, M., Kas, M., van Engeland, H., et al. (2010). Dissecting the clinical heterogeneity of autism spectrum disorders through defined genotypes. PLOS ONE 5:e10887. doi:10.1371/journal.pone. 0010887

Carter, A. S., Messinger, D. S., Stone, W. L., Celimli, S., Nahmias, A. S., and Yoder, P. (2011). A randomized controlled trial of Hanen's 'More Than Words' in toddlers with early autism symptoms. J. Child Psychol. Psychiatry 52, 741-752. doi:10.1111/j.14697610.2011.02395.x

Ceponiene, R., Alku, P., Westerfield, M., Torki, M., and Townsend, J. (2005). ERPs differentiate syllable and nonphonetic sound processing in children and adults. Psychophysiology 42, 391-406. doi:10.1111/j. 1469-8986.2005.00305.x

Charman, T. (2003). Why is joint attention a pivotal skill in autism? Philos. Trans. R. Soc. Lond. B Biol. Sci. 358, 315-324. doi:10.1098/rstb. 2002.1199

Charman, T., Jones, C., Pickles, A., Simonoff, E., Baird, G., and Happé, F. (2011). Defining the cognitive phenotype of autism. Brain Res. 1380, 10-21. doi:10.1016/j.brainres.2010. 10.075

Chen, F. S., and Yoon, J. M. (2011). Brief report: broader autism phenotype predicts spontaneous reciprocity of direct gaze. J. Autism Dev. Disord. 41, 1131-1134. doi:10.1007/s10803010-1136-2

Clarke, R., and Eapen, V. (in press). Balance within the neurexin transsynaptic connexus functions as a gate-keeper of behavioural control. Front. Psychiatry

Constantino, J. N., and Todd, R. D. (2003). Autistic traits in the general population: a twin study. Arch. Gen. Psychiatry 60, 524. doi:10.1001/ archpsyc.60.5.524

Constantino, J. N., and Todd, R. D. (2005). Intergenerational transmission of subthreshold autistic traits in the general population. Biol. Psychiatry 57, 655-660. doi:10.1016/j. biopsych.2004.12.014

Courchesne, E., Campbell, K., and Solso, S. (2011). Brain growth across the life span in autism: age-specific changes in anatomical pathology. Brain Res. 1380, 138-145. doi:10. 1016/j.brainres.2010.09.101

task ahead is certainly great, but also tantalizing with respect to the potential refinements in our understanding and also benefits to affected individuals that are possible.

Courchesne, E., Redcay, E., Morgan, J. T., and Kennedy, D. P. (2005). Autism at the beginning: microstructural and growth abnormalities underlying the cognitive and behavioral phenotype of autism. Dev. Psychopathol. 17, 577-597. doi:10.1017/ S0954579405050285

Dawson, G. (2008). Early behavioral intervention, brain plasticity, and the prevention of autism spectrum disorder. Dev. Psychopathol. 20, 775. doi:10.1017/S0954579408000370

Dawson, G., Jones, E., Merkle, K., Venema, K., Lowy, R., Faja, S., et al. (2012). Early behavioral intervention is associated with normalized brain activity in young children with autism. J. Am. Acad. Child Adolesc. Psychiatry 51, 1150-1159. doi: 10.1016/j.jaac.2012.08.018

Dawson, G., Meltzoff, A. N., Osterling, J., Rinaldi, J., and Brown, E. (1998). Children with autism fail to orient to naturally occurring social stimuli. J. Autism Dev. Disord. 28, 479-485. doi:10.1023/A:1026043926488

Dawson, G., Rogers, S., Munson, J., Smith, M., Winter, J., Greenson, J., et al. (2010). Randomized, controlled trial of an intervention for toddlers with autism: the Early Start Denver Model. Pediatrics 125, e17-e23. doi:10.1542/peds.2009-0958

Dawson, G., Toth, K., Abbott, R., Osterling, J., Munson, J., Estes, A., et al. (2004). Early social attention impairments in autism: social orienting, joint attention, and attention to distress. Dev. Psychol. 40, 271-282. doi:10.1037/0012-1649.40.2.271

Dawson, G., Webb, S., Schellenberg, G. D., Dager, S., Friedman, S., Aylward, E., et al. (2002). Defining the broader phenotype of autism: genetic, brain, and behavioral perspectives. Dev. Psychopathol. 14, 581-611. doi:10. 1017/S0954579402003103

Eapen, V. (2011). Genetic basis of autism: is there a way forward? Curr. Opin. Psychiatry 24, 226. doi:10. 1097/YCO.0b013e328345927e

Eapen, V., Crncec, R., and Walter, A. (2013). Clinical outcomes of an early intervention program for preschool children with Autism Spectrum Disorder in a community group setting. BMC Pediatr. 13:3. doi:10.1186/ 1471-2431-13-3

Ecker, C., Suckling, J., Deoni, S. C., Lombardo, M. V., Bullmore, E. T., Baron-Cohen, S., et al. (2012). Brain anatomy and its relationship to behavior in adults with autism spectrum disorder: a multicenter magnetic resonance imaging study. Arch. Gen. Psychiatry 69, 195. doi:10. 1001/archgenpsychiatry.2011.1251

Eikeseth, S., Smith, T., Jahr, E., and Eldevik, S. (2007). Outcome for children with autism who began intensive behavioral treatment between ages 4 and 7 a comparison controlled study. Behav. Modif. 31, 264-278. doi:10.1177/0145445506291396

Eldevik, S., Eikeseth, S., Jahr, E., and Smith, T. (2006). Effects of lowintensity behavioral treatment for children with autism and mental retardation. J. Autism Dev. Disord. 36, 211-224. doi:10.1007/s10803005-0058- $\mathrm{x}$

El-Fishawy, P. (2010). The genetics of autism: key issues, recent findings and clinical implications. Psychiatr. Clin. North Am. 33, 83. doi:10.1016/ j.psc.2009.12.002

Elsabbagh, M. (2012). The emerging autistic brain: processes of risk and resilience. Neuropsychiatry 2, 181-183. doi:10.2217/npy.12.29

Elsabbagh, M., Mercure, E., Hudry, K., Chandler, S., Pasco, G., Charman, T., et al. (2012). Infant neural sensitivity to dynamic eye gaze is associated with later emerging autism. Curr. Biol. 22, 338-342. doi:10.1016/ j.cub.2011.12.056

Flanagan, H. E., Perry, A., and Freeman, N. L. (2012). Effectiveness of large-scale community-based intensive behavioral Intervention: a waitlist comparison study exploring outcomes and predictors. Res. Autism Spectr. Disord. 6, 673-682. doi:10. 1016/j.rasd.2011.09.011

Frazier, T. W., Youngstrom, E. A., Sinclair, L., Kubu, C. S., Law, P., Rezai, A., et al. (2010). Autism spectrum disorders as a qualitatively distinct category from typical behavior in a large, clinically ascertained sample. Assessment 17, 308-320. doi:10. 1177/1073191109356534

Frazier, T. W., Youngstrom, E. A., Speer, L., Embacher, R., Law, P., Constantino, J., et al. (2012). Validation of proposed DSM- 5 criteria for autism spectrum disorder. J. Am. Acad. Child Adolesc. Psychiatry 51, e23. doi:10.1016/j.jaac.2011.09.021

Friedman, J. I., Vrijenhoek, T., Markx, S., Janssen, I. M., van der Vliet, W. A., Faas, B. H., et al. (2008). CNTNAP2 gene dosage variation is associated with schizophrenia and epilepsy. Mol. Psychiatry 13, 261-266. doi:10. 1038/sj.mp.4002049 
Georgiades, S., Szatmari, P., and Boyle, M. (2013). Importance of studying heterogeneity in autism. Neuropsychiatry 3, 123-125. doi:10.2217/npy. 13.8

Geschwind, D. H., and Levitt, P. (2007). Autism spectrum disorders: developmental disconnection syndromes. Curr. Opin. Neurobiol. 17, 103-111. doi:10.1016/j.conb.2007.01.009

Goussé, V., Plumet, M.-H., Chabane, N., Mouren-Siméoni, M.-C., Ferradian, N., and Leboyer, M. (2002). Fringe phenotypes in autism: a review of clinical, biochemical and cognitive studies. Eur. Psychiatry 17, 120-128. doi:10.1016/S09249338(02)00640-5

Granpeesheh, D., Tarbox, J., and Dixon, D. R. (2009). Applied behavior analytic interventions for children with autism: a description and review of treatment research. Ann. Clin. Psychiatry 21, 162-173.

Grinter, E. J., Van Beek, P. L., Maybery, M. T., and Badcock, D. R. (2009). Brief report: visuospatial analysis and self-rated autistic-like traits. $J$. Autism Dev. Disord. 39, 670-677. doi:10.1007/s10803-008-0658-3

Grove, R., Baillie, A., Allison, C., BaronCohen, S., and Hoekstra, R. A. (2013). Empathizing, systemizing, and autistic traits: latent structure in individuals with autism, their parents, and general population controls. J. Abnorm. Psychol. 122, 600-609. doi:10.1037/a0031919

Happe, F., and Frith, U. (2006). The weak coherence account: detail-focused cognitive style in autism spectrum disorders. J. Autism Dev. Disord. 36, 5-25. doi:10.1007/s10803-005-0039-0

Happe, F., Ronald, A., and Plomin, R. (2006). Time to give up on a single explanation for autism. Nat. Neurosci. 9, 1218-1220. doi:10.1038/ nn 1770

Harris, S. L., and Handleman, J. S. (2000). Age and IQ at intake as predictors of placement for young children with autism: a four-to sixyear follow-up. J. Autism Dev. Disord. 30, 137-142. doi:10.1023/A: 1005459606120

Hawes, D. J., and Dadds, M. R. (2005). The treatment of conduct problems in children with callousunemotional traits. J. Consult. Clin. Psychol. 73, 737-741. doi:10.1037/ 0022-006X.73.4.737

Hawes, D. J., and Dadds, M. R. (2007). Stability and malleability of callousunemotional traits during treatment for childhood conduct problems. J. Clin. Child Adolesc. Psychol. 36, 347-355.
Hawes, D. J., Dadds, M. R., Brennan, J., Rhodes, T., and Cauchi, A. (2013). Revisiting the treatment of conduct problems in children with callousunemotional traits. Aust. N. Z. J. Psychiatry 47, 646-653. doi:10.1177/ 0004867413484092

Howlin, P., Magiati, I., and Charman, T. (2009). Systematic review of early intensive behavioral interventions for children with autism. Am. J. Intellect. Dev. Disabil. 114, 23-41. doi:10. 1352/2009.114:23

Ingersoll, B. (2010a). Brief report: pilot randomized controlled trial of reciprocal imitation training for teaching elicited and spontaneous imitation to children with autism. J. Autism Dev. Disord. 40, 1154-1160. doi:10.1007/s10803010-0966-2

Ingersoll, B. (2010b). Broader autism phenotype and nonverbal sensitivity: evidence for an association in the general population. J. Autism Dev. Disord. 40, 590-598. doi:10.1007/ s10803-009-0907-0

Ingram, D. G., Takahashi, T. N., and Miles, J. H. (2008). Defining autism subgroups: a taxometric solution. J. Autism Dev. Disord. 38, 950-960. doi:10.1007/s10803-007-0469-y

Jones, W., Carr, K., and Klin, A. (2008). Absence of preferential looking to the eyes of approaching adults predicts level of social disability in 2year-old toddlers with autism spectrum disorder. Arch. Gen. Psychiatry 65, 946. doi:10.1001/archpsyc.65. 8.946

Kanner, L. (1943). Autistic disturbances of affective contact. Nerv. Child 2, 217-250.

Kasari, C., Gulsrud, A., Freeman, S., Paparella, T., and Hellemann, G. (2012). Longitudinal follow-up of children with autism receiving targeted interventions on joint attention and play. J. Am. Acad. Child Adolesc. Psychiatry 51, 487-495. doi:10. 1016/j.jaac.2012.02.019

Kasari, C., Paparella, T., Freeman, S., and Jahromi, L. B. (2008). Language outcome in autism: randomized comparison of joint attention and play interventions. J. Consult. Clin. Psychol. 76, 125. doi:10.1037/ 0022-006X.76.1.125

Klin, A. (1991). Young autistic children's listening preferences in regard to speech: a possible characterization of the symptom of social withdrawal. J. Autism Dev. Disord. 21, 29-42. doi:10.1007/BF02206995

Klin, A., Jones, W., Schultz, R., and Volkmar, F. (2003). The enactive mind, or from actions to cognition: lessons from autism. Philos. Trans. R. Soc.
Lond. B Biol. Sci. 358, 345-360. doi: 10.1098/rstb.2002.1202

Klin, A., Jones, W., Schultz, R., Volkmar, F., and Cohen, D. (2002). Defining and quantifying the social phenotype in autism. Am. J. Psychiatry 159, 895-908. doi:10.1176/appi.ajp. 159.6.895

Klin, A., Lin, D. J., Gorrindo, P., Ramsay, G., and Jones, W. (2009). Two-yearolds with autism orient to non-social contingencies rather than biological motion. Nature 459, 257-261. doi:10.1038/nature07868

Kuhl, P. K., Coffey-Corina, S., Padden, D., and Dawson, G. (2005). Links between social and linguistic processing of speech in preschool children with autism: behavioral and electrophysiological measures. Dev. Sci. 8, F1-F12. doi:10.1111/j.14677687.2004.00384.x

Kuhl, P. K., Coffey-Corina, S., Padden, D., Munson, J., Estes, A., and Dawson, G. (2013). Brain responses to words in 2-year-olds with autism predict developmental outcomes at age 6. PLOS ONE 8:e64967. doi:10. 1371/journal.pone.0064967

Lai, M. C., Lombardo, M. V., Ruigrok, A. N., Chakrabarti, B., Wheelwright, S. J., Auyeung, B., et al. (2012). Cognition in males and females with autism: similarities and differences. PLoS ONE 7:e47198. doi:10.1371/ journal.pone.0047198

Latham, K., Chung, S. T., Allen, P. M., Tavassoli, T., and Baron-Cohen, S. (2013). Spatial localisation in autism: evidence for differences in early cortical visual processing. $\mathrm{Mol}$. Autism 4, doi:10.1186/2040-2392-44

Lepistö, T., Kujala, T., Vanhala, R., Alku, P., Huotilainen, M., and Näätänen, R. (2005). The discrimination of and orienting to speech and non-speech sounds in children with autism. Brain Res. 1066, 147-157. doi:10. 1016/j.brainres.2005.10.052

Losh, M., Adolphs, R., Poe, M. D., Couture, S., Penn, D., Baranek, G. T., et al. (2009). Neuropsychological profile of autism and the broad autism phenotype. Arch. Gen. Psychiatry 66, 518. doi:10.1001/archgenpsychiatry. 2009.34

Magiati, I., Charman, T., and Howlin, P. (2007). A two-year prospective follow-up study of communitybased early intensive behavioural intervention and specialist nursery provision for children with autism spectrum disorders. J. Child Psychol. Psychiatry 48, 803-812. doi:10.1111/ j.1469-7610.2007.01756.x

Makrygianni, M. K., and Reed, P. (2010). A meta-analytic review of the effectiveness of behavioural early intervention programs for children with Autistic Spectrum Disorders. Res. Autism Spectr. Disord. 4, 577-593.

Mandy, W. P., and Skuse, D. H. (2008). Research review: what is the association between the socialcommunication element of autism and repetitive interests, behaviours and activities? J. Child Psychol. Psychiatry 49, 795-808. doi:10.1111/j. 1469-7610.2008.01911.x

McDonald, R., Dodson, M. C., Rosenfield, D., and Jouriles, E. N. (2011). Effects of a parenting intervention on features of psychopathy in children. J. Abnorm. Child Psychol. 39, 1013-1023. doi:10.1007/s10802011-9512-8

McEachin, J. J., Smith, T., and Lovaas, O. (1993). Long-term outcome for children with autism who received early intensive behavioral treatment. Am. J. Ment. Retard. 97, 359-359.

McIntosh, D. N., Reichmann-Decker, A., Winkielman, P., and Wilbarger, J. L. (2006). When the social mirror breaks: deficits in automatic, but not voluntary, mimicry of emotional facial expressions in autism. Dev Sci. 9, 295-302. doi:10.1111/j.14677687.2006.00492.x

Miles, J. H., Takahashi, T. N., Bagby, S., Sahota, P. K., Vaslow, D. F., Wang, C. H., et al. (2005). Essential versus complex autism: definition of fundamental prognostic subtypes. Am. J. Med. Genet. A 135 , 171-180.

Mottron, L., Dawson, M., Soulieres, I., Hubert, B., and Burack, J. (2006). Enhanced perceptual functioning in autism: an update, and eight principles of autistic perception. J. Autism Dev. Disord. 36, 27-43. doi:10.1007/ s10803-005-0040-7

Munson, J., Dawson, G., Sterling, L., Beauchaine, T., Zhou, A., Elizabeth, K., et al. (2008a). Evidence for latent classes of IQ in young children with autism spectrum disorder. Am. J. Ment. Retard. 113, 439-452. doi:10. 1352/2008.113:439-452

Munson, J., Faja, S., Meltzoff, A., Abbott, R., and Dawson, G. (2008b). Neurocognitive predictors of social and communicative developmental trajectories in preschoolers with autism spectrum disorders. J. Int. Neuropsychol. Soc. 14, 956-966. doi:10.1017/ S1355617708081393

Nadig, A. S., Ozonoff, S., Young, G. S., Rozga, A., Sigman, M., and Rogers, S. J. (2007). A prospective study of response to name in infants at risk for autism. Arch. Pediatr. Adolesc. Med. 161, 378. 
Norbury, C. F., Brock, J., Cragg, L., Einav, S., Griffiths, H., and Nation, K. (2009). Eye-movement patterns are associated with communicative competence in autistic spectrum disorders. J. Child Psychol. Psychiatry 50, 834-842. doi:10.1111/j.14697610.2009.02073.x

Oberman, L. M., Winkielman, P., and Ramachandran, V. S. (2009). Slow echo: facial EMG evidence for the delay of spontaneous, but not voluntary, emotional mimicry in children with autism spectrum disorders. Dev. Sci. 12, 510-520. doi:10.1111/j.1467-7687. 2008.00796.x

Oerlemans, A., Meer, J. J., Steijn, D., Ruiter, S., Bruijn, Y. E., Sonneville, L. J., et al. (2013). Recognition of facial emotion and affective prosody in children with ASD (+ADHD) and their unaffected siblings. Eur. Child Adolesc. Psychiatry 1-15. doi: 10.1007/s00787-013-0446-2

O'Roak, B. J. (2008). Autism genetics: strategies, challenges, and opportunities. Autism Res. 1, 4-17. doi:10. 1002/aur.3

Osterling, J. A., Dawson, G., and Munson, J. A. (2002). Early recognition of 1-year-old infants with autism spectrum disorder versus mental retardation. Dev. Psychopathol. 14, 239-251. doi:10.1017/ S0954579402002031

Ozonoff, S., Pennington, B. F., and Rogers, S. J. (1991). Executive function deficits in high-functioning autistic individuals: relationship to theory of mind. J. Child Psychol. Psychiatry 32, 1081-1105. doi:10.1111/ j.1469-7610.1991.tb00351.x

Perrin, J. M., Coury, D. L., Jones, N., and Lajonchere, C. (2012). The autism treatment network and autism intervention research network on physical health: future directions. Pediatrics 130, S198-S201. doi:10.1542/ peds.2012-0900S

Perry, A., Cummings, A., Geier, J. D., Freeman, N. L., Hughes, S., Managhan, T., et al. (2011). Predictors of outcome for children receiving intensive behavioral intervention in a large, community-based program. Res. Autism Spectr. Disord. 5, 592-603. doi:10.1016/j.rasd.2010. 07.003

Pinto, D., Pagnamenta, A. T., Klei, L., Anney, R., Merico, D., Regan, R., et al. (2010). Functional impact of global rare copy number variation in autism spectrum disorders. Nature 466, 368-372. doi:10.1038/ nature 09146

Piven, J., and Palmer, P. (1999). Psychiatric disorder and the broad autism phenotype: evidence from a family study of multiple-incidence autism families. Am. J. Psychiatry 156, 557-563.

Plaisted, K. C. (2001). "Reduced generalisation in autism: an alternative to weak central coherence," in The Development of Autism: Perspectives from Theory and Research, eds J. A. Burack, T. Charman, N. Yirmiya, and P. R. Zelazo (Nahwah, NJ: Erlbaum), 149-169.

Reichow, B. (2012). Overview of metaanalyses on early intensive behavioral intervention for young children with autism spectrum disorders. J. Autism Dev. Disord. 42, 512-520. doi:10.1007/s10803-0111218-9

Remington, B., Hastings, R. P., Kovshoff, H., degli Espinosa, F., Jahr, E., Brown, T., et al. (2007). Early intensive behavioral intervention: outcomes for children with autism and their parents after two years. Am. J. Ment. Retard. 112 , 418-438. doi:10.1352/08958017(2007)112[418:EIBIOF]2.0. $\mathrm{CO} ; 2$

Richmond, L. L., Thorpe, M., Berryhill, M. E., Klugman, J., and Olson, I. R. (2013). Individual differences in autistic trait load in the general population predict visual working memory performance. Q. J. Exp. Psychol. 66, 1182-1195. doi:10.1080/17470218. 2012.734831

Russo, N., Nicol, T., Trommer, B., Zecker, S., and Kraus, N. (2009). Brainstem transcription of speech is disrupted in children with autism spectrum disorders. Dev. Sci. 12, 557-567. doi:10.1111/j.1467-7687. 2008.00790.x

Sallows, G. O., and Graupner, T. D. (2005). Intensive behavioral treatment for children with autism: fouryear outcome and predictors. Am. J. Ment. Retard. 110, 417-438.

Sasson, N. J., Nowlin, R. B., and Pinkham, A. E. (2012). Social cognition, social skill, and the broad autism phenotype. Autism. doi: 10.1177/1362361312455704. [Epub ahead of print].

Schreibman, L., Stahmer, A. C., Barlett, V. C., and Dufek, S. (2009). Brief report: toward refinement of a predictive behavioral profile for treatment outcome in children with autism. Res. Autism Spectr. Disord. 3, 163-172. doi:10.1016/j.rasd.2008. 04.008

Smith, T., Groen, A. D., and Wynn, J. W. (2000). Randomized trial of intensive early intervention for children with pervasive developmental disorder. Am. J. Ment. Retard. 105, 269-285. doi:10.1352/0895-8017(2000) 105<0269:RTOIEI > 2.0.CO;2

Spencer, M., Chura, L., Holt, R., Suckling, J., Calder, A., Bullmore, E., et al. (2012a). Failure to deactivate the default mode network indicates a possible endophenotype of autism. Mol. Autism 3, 1-9. doi:10.1186/ 2040-2392-3-15

Spencer, M., Holt, R., Chura, L., Calder, A., Suckling, J., Bullmore, E., et al. (2012b). Atypical activation during the Embedded Figures Task as a functional magnetic resonance imaging endophenotype of autism. Brain 135, 3469-3480. doi:10.1093/ brain/aws229

Spencer, M., Holt, R., Chura, L., Suckling, J., Calder, A., Bullmore, E., et al. (2011). A novel functional brain imaging endophenotype of autism: the neural response to facial expression of emotion. Transl. Psychiatry 1, e19. doi:10.1038/tp.2011.18

Stahmer, A. C., Schreibman, L., and Cunningham, A. B. (2011). Toward a technology of treatment individualization for young children with autism spectrum disorders. Brain Res. 1380, 229-239. doi:10.1016/j. brainres.2010.09.043

Stewart, M. E., and Ota, M. (2008) Lexical effects on speech perception in individuals with "autistic" traits. Cognition 109, 157-162. doi:10.1016/j.cognition. 2008.07.010

Stewart, M. E., Watson, J., Allcock, A.J., and Yaqoob, T. (2009). Autistic traits predict performance on the block design. Autism 13, 133-142. doi:10.1177/1362361308098515

Sucksmith, E., Allison, C., BaronCohen, S., Chakrabarti, B., and Hoekstra, R. (2012). Empathy and emotion recognition in people with autism, first-degree relatives, and controls. Neuropsychologia 51, 98-105. doi:10.1016/j. neuropsychologia.2012.11.013

Taylor, L. J., Maybery, M. T., and Whitehouse, A. J. (2012). Do children with specific language impairment have a cognitive profile reminiscent of autism? A review of the literature. J. Autism Dev. Disord. 42, 2067-2083. doi:10.1007/s10803012-1456-5

Verkerk, A. J., Mathews, C. A., Joosse, M., Eussen, B. H., Heutink, P., Oostra, B. A., et al. (2003). CNTNAP2 is disrupted in a family with Gilles de la Tourette syndrome and obsessive compulsive disorder. Genomics 82, 1-9. doi:10. 1016/S0888-7543(03)00097-1
Viding, E., Frick, P. J., and Plomin, R. (2007). Aetiology of the relationship between callous-unemotional traits and conduct problems in childhood. Br. J. Psychiatry Suppl. 190, s33-s38. doi:10.1192/bjp.190.5.s33

Vismara, L. A., and Rogers, S. J. (2010). Behavioral treatments in autism spectrum disorder: what do we know? Annu. Rev. Clin. Psychol. 6, 447-468. doi:10.1146/annurev. clinpsy.121208.131151

Vivanti, G., Dissanayake, C., Zierhut, C. and Rogers, S. J. (2013). Brief report: predictors of outcomes in the early start Denver model delivered in a group setting. J. Autism Dev. Disord. 43, 1717-1724. doi:10.1007/s10803012-1705-7

von dem Hagen, E. A., Stoyanova, R. S., Baron-Cohen, S., and Calder, A. J. (2013). Reduced functional connectivity within and between 'social' resting state networks in Autism Spectrum Conditions. Soc. Cogn. Affect. Neurosci. 8, 694-701. doi:10. $1093 /$ scan/nss053

Wallace, K. S., and Rogers, S. J. (2010). Intervening in infancy: implications for autism spectrum disorders. J. Child Psychol. Psychiatry 51, 1300-1320. doi:10.1111/j.14697610.2010.02308.x

Wang, K., Zhang, H., Ma, D., Bucan, M., Glessner, J. T., Abrahams, B. S., et al. (2009). Common genetic variants on 5 p14. 1 associate with autism spectrum disorders. Nature 459, 528-533. doi:10.1038/nature07999

Warren, Z., McPheeters, M. L., Sathe, N., Foss-Feig, J. H., Glasser, A., and Veenstra-VanderWeele, J. (2011). A systematic review of early intensive intervention for autism spectrum disorders. Pediatrics 127, e1303-e1311. doi:10.1542/peds.2011-0426

Waschbusch, D. A., Carrey, N. J., Willoughby, M. T., King, S., and Andrade, B. F. (2007). Effects of methylphenidate and behavior modification on the social and academic behavior of children with disruptive behavior disorders: the moderating role of callous/unemotional traits. J. Clin. Child Adolesc. Psychol. 36, 629-644.

Werner, E., and Dawson, G. (2005). Validation of the phenomenon of autistic regression using home videotapes. Arch. Gen. Psychiatry 62, 889. doi:10.1001/archpsyc.62.8.889

Werner, E., Dawson, G., Osterling, J., and Dinno, N. (2000). Brief report: recognition of autism spectrum disorder before one year of age: a retrospective study based on home videotapes. J. Autism Dev. 
Disord. 30, 157-162. doi:10.1023/A: 1005463707029

Wheelwright, S., Auyeung, B., Allison, C., and Baron-Cohen, S. (2010). Research defining the broader, medium and narrow autism phenotype among parents using the Autism Spectrum Quotient (AQ). Mol. Autism 1:10. doi:10.1186/20402392-1-10

Whitehouse, A. J., and Bishop, D. V. (2008). Do children with autism 'switch off' to speech sounds? An investigation using event-related potentials. Dev. Sci. 11, 516-524. doi: 10.1111/j.1467-7687.2008.00697.x
Wing, L. (1996). The Autistic Spectrum: A Guide for Parents and Professionals. London: Constable.

Yoder, P., and Stone, W. L. (2006). Randomized comparison of two communication interventions for preschoolers with autism spectrum disorders. J. Consult. Clin. Psychol. 74, 426. doi:10.1037/0022-006X.74. 3.426

Zwaigenbaum, L., Bryson, S., Rogers, T., Roberts, W., Brian, J., and Szatmari, P. (2005). Behavioral manifestations of autism in the first year of life. Int. J. Dev. Neurosci. 23, 143-152. doi:10.1016/j.ijdevneu.2004.05.001
Conflict of Interest Statement: The authors declare that the research was conducted in the absence of any commercial or financial relationships that could be construed as a potential conflict of interest.

Received: 06 June 2013; accepted: 26 August 2013; published online: 11 September 2013.

Citation: Eapen V, Črnčec $R$ and Walter A (2013) Exploring links between genotypes, phenotypes, and clinical predictors of response to early intensive behavioral intervention in autism spectrum disorder. Front. Hum. Neurosci. 7:567 doi: 10.3389/fnhum.2013.00567

This article was submitted to the journal Frontiers in Human Neuroscience.

Copyright (c) 2013 Eapen, Črnčec and Walter. This is an open-access article distributed under the terms of the Creative Commons Attribution License (CC BY). The use, distribution or reproduction in other forums is permitted, provided the original author(s) or licensor are credited and that the original publication in this journal is cited, in accordance with accepted academic practice. No use, distribution or reproduction is permitted which does not comply with these terms. 